\title{
A cognitive behavioural perspective on the relationship between childhood trauma and psychosis
}

\author{
ANTHONY P. MORRISON ${ }^{1,2}$ \\ ${ }^{1}$ School of Psychological Sciences, University of Manchester, Manchester (United Kingdom) \\ ${ }^{2}$ Psychosis Research Unit, GMWMHFT
}

\begin{abstract}
This editorial reviews the relationship between childhood trauma and the development of psychosis in adulthood. There are numerous studies, including large, prospective studies, which clearly support a link between childhood adversity and experience of psychosis later in life. There is also evidence that there is a dose response relationship, and that childhood trauma is particularly associated with the experience of hallucinations and delusional ideas. It is possible that psychosis is a relatively understandable response to the experience of severe trauma, and recent cognitive models of psychosis can help to explain the underlying mechanisms in such a causal relationship. There are obvious treatment implications, which include the need to assess histories of childhood trauma in people with psychosis, the incorporation of trauma in shared understandings of psychosis with service users, the incorporation of change strategies in cognitive behaviour therapy for psychosis that are derived from evidence-based approaches to the treatment of trauma and PTSD, and the prevention of traumatisation by mental health services.

Declaration of Interest: None.
\end{abstract}

KEY WORDS: sexual abuse in childhood, psychosis, mechanism of psychiatric symptoms.

\section{IS THERE EVIDENCE THAT CHILDHOOD TRAUMA CAUSES PSYCHOSIS?}

There are clearly complex and multiple relationships between childhood trauma and psychosis (Morrison et al., 2003a; Read, 1997; Read et al., 2005). It appears likely that, at least for some people, psychosis can be a reaction to traumatic experiences in childhood, given the prevalence of such experiences in people with psychosis and the links in relation to form and content of psychotic experiences (Read et al., 2005). For example, a consistent finding in research studies is that childhood sexual abuse seems to be specifically associated with the development of critical or commanding voices in adulthood (Read et al., 2004). Such findings have also been demonstrated across the continuum of psychotic experiences, with similar results in non-clinical populations (Morrison \& Petersen, 2003) and in people at ultra-high risk of developing psychosis (Thompson et al., 2009).

Address for correspondence: Professor T. Morrison, School of Psychological Sciences, University of Manchester, Manchester M13 9PL (United Kingdom).

E-mail: tony.morrison@manchester.ac.uk
Many studies of the general population have now demonstrated an increased risk of developing psychosis is associated with childhood trauma. Large longitudinal studies from several countries have shown a clear link between childhood trauma and psychosis. For example, a recent Dutch study with over 4000 participants showed that a sexual or physical assault in childhood or in adult life is associated with psychosis in adulthood (Janssen et al., 2004). A large British study with over 8000 participants showed that bullying has also emerged as a potent aetiological factor in the development of psychosis (Bebbington et al., 2004). Another large study, using data from the US National Comorbidity Survey showed that childhood physical abuse predicted psychosis, and that there was a significant cumulative relationship between trauma and psychosis, with number of trauma types experienced increasing the probability of psychosis (Shevlin et al., 2007). There are also large population based studies that have shown specific links between childhood trauma and both delusions (Scott et al.,2007) and hallucinations (Whitfield et al., 2005). Many of these studies have demonstrated a dose-response relationship (Janssen et al., 2004; Scott et al., 2007; Whitfield et al., 2005) in which greater numbers of traumatic events conferred greater risk of experiencing psychosis. 


\section{HOW CAN CHILDHOOD TRAUMA CAUSE PSYCHOSIS?}

Despite a recent increase in research devoted to this topic, there are relatively few studies that examine the mechanisms that may explain how trauma may increase vulnerability to psychosis. It is likely that psychotic experiences are essentially normal phenomena that occur on a continuum in the general population (Johns \& van Os, 2001; van Os, 2003). It is, therefore, possible that childhood traumatic experiences cause psychotic phenomena in the same way that they appear to predispose people to other forms of psychological symptoms and distress (such as anxiety, dissociative experiences, depression). For example, several studies of school children and adolescents have shown that childhood trauma including bullying, neglect, physical assault and sexual assault are associated with psychotic experiences, using both interview based methods (Kelleher et al., 2008) and self-report measures (Campbell \& Morrison, 2007; Lataster et al., 2006). It has also been shown that this is independent of any family history of psychosis or comorbid psychiatric difficulties (Kelleher et al., 2008). Similarly, it has been shown that psychotic experiences such as auditory and visual hallucinations are a common response to sexual assault in young people with no prior psychiatric history (Kilcommons et al., 2008). This approach is encapsulated in Read and Haslam's summary of public opinion on the matter: "Bad things happen and can drive you crazy" (Read \& Haslam, 2004).

It is also possible that the experience of trauma in childhood may mediate the need for care or help-seeking behaviour in people with psychotic experiences. The occurrence of trauma in the life history of a person experiencing hallucinatory voices has been shown to discriminate between patients and non-patients (Honig et al., 1998). A large, prospective study of the general population (Bak et al., 2005) found that there is a high prevalence of trauma in people who have psychotic experiences associated with distress, whereas those without distress had a low prevalence of trauma. Therefore, consistent with predictions of cognitive models (Morrison et al., 2003a), trauma may predispose people to appraising their unusual experiences in a problematic way.

Recent psychological models of psychosis (Bentall, 2003; Garety et al., 2001; Morrison, 2001) may also help to explain the relationship between the experience of trauma and the development of psychotic experiences and becoming a patient with a psychotic diagnosis; there may be several ways in which traumatic experiences may confer vulnerability to psychosis via cognitive and behavioural processes (Morrison et al., 2003a). It is possible that the cognitive and behavioural consequences of trauma may make people vulnerable to psychosis. Negative beliefs about self, world and others (such as 'I am vulnerable' and 'Other people are dangerous') have been shown to be associated with the development of psychotic experiences (Bentall et al., 2001; Garety et al., 2001; Morrison, 2001); a recent study has also shown that such beliefs specifically formed as a result of trauma are related to psychotic experiences in patients (Kilcommons \& Morrison, 2005). Positive beliefs about psychotic experiences (such as 'paranoia is a helpful survival strategy' or 'hearing voices helps me to cope') may also be related to traumatic experience, and have been shown to be associated with the development of psychosis, in both nonpatients (Morrison et al., 2005) and patients with schizophrenia-spectrum diagnoses (Morrison et al., submitted for publication). In addition to beliefs formed as a result of trauma predisposing people to psychosis, it is also possible that the unhelpful responses that people often adopt in relation to psychotic experiences, which contribute to the maintenance of psychosis, may be influenced by childhood trauma. For example, unhelpful thought control strategies, such as punishment and distraction, have been linked to trauma (Reynolds \& Wells, 1999) and are utilised by patients meeting criteria for schizophrenia (Morrison \& Wells, 2000). Similarly, reliance on avoidance, dissociation and substance use are common in victims of abuse, and clearly contribute to the maintenance of psychotic experiences (Mueser et al., 2002). It has also been shown that psychiatric voice hearers with predominantly negative beliefs about voices had higher levels of childhood sexual abuse in comparison with non-psychiatric voice hearers with predominantly positive beliefs about voices, and that the psychiatric voice hearers were more likely to resist their voices and less likely to engage with them (Andrew et al., 2008), which is consistent with predictions of trauma-related psychological models of psychosis (Morrison et al., 2003a).

Finally, it may be that the neurodevelopmental impact of childhood trauma could also account for the development of psychosis, as many of the neurobiological findings that characterise brain structure and chemistry in patients meeting criteria for schizophrenia are also found in the developing brains of traumatised children (Read et al., 2001).

\section{CHILDHOOD TRAUMA AND PSYCHOSIS: IMPLICATIONS FOR PRACTICE}

There are several clinical implications of this approach to understanding psychosis. The research on childhood trauma and psychosis highlights the need to

Epidemiologia e Psichiatria Sociale, 18, 4, 2009 
ask service users about traumatic events in their life history. Currently most child abuse cases, for example, remain undetected by mental health services internationally (Read et al., 2005). There is also evidence that this is especially the case for people with diagnoses indicative of psychosis, and that mental health staff with strong bio-genetic causal beliefs are particularly unlikely to ask about childhood trauma (Young et al., 2001). It is clear that failure to enquire about childhood trauma can result in suboptimal (or even inappropriate) clinical care and can prolong distress unnecessarily. Therefore, the adoption of standardised approaches to asking about and responding to trauma histories in people with psychosis (Read \& Fraser, 1998a, b) should be developed; this could be done using validated semi-structured clinical interviews (Green, 1996; Mueser et al., 1998) or self-report measures (Bernstein et al., 1994; Bifulco et al., 2005).

Helping service users to identify any links between their traumatic experiences and current psychotic symptoms via the development of a shared formulation may help to normalise their experiences, reduce their distress and increase their perceived control. It will also validate their experiences and enable them to feel listened to and understood. If the case formulation supports an association between childhood trauma and adult psychotic experiences, then the application of change methods that are derived from evidence-based psychological therapies for trauma and PTSD would seem appropriate; for example, examining the idiosyncratic meaning of the trauma or the sequelae of the trauma and developing an explanatory narrative for the trauma to aid contextualisation in memory (Ehlers \& Clark, 2000). There is emerging evidence that strategies based on this approach, which also include normalisation of reactions (e.g. intrusive symptoms, flashbacks, hallucinations and paranoia), grounding techniques for dissociative experiences, modification of trauma-related imagery, schema change methods and reducing current sense of threat can all be helpful in reducing distress, increasing perceived control and improving quality of life (Larkin \& Morrison, 2006). There is already a strong evidence base for many of these interventions as they are often included within cognitive behaviour therapy for psychosis (Chadwick et al., 1996; Fowler et al., 1995; Kingdon \& Turkington, 2005; Kuipers \& Bebbington, 2006; Morrison et al., 2003b), but there is little treatment research focusing specifically on those with a clear involvement of childhood trauma in the development of their psychosis.

If psychosis is related to previous trauma, then we have a significant responsibility to ensure that treatment experiences themselves are not traumatising. This is important, since there is good evidence to suggest that experiences, such as acute psychiatric admissions and compulsory administration of medication, are traumatising for service users (Frame \& Morrison, 2001; Jackson et al., 2004; Katsakou \& Priebe, 2007; McGorry et al., 1991). From a broader perspective, the causal role of adverse life events in psychosis would seem to imply that psychosis may be as preventable as other mental health difficulties and that the mental health community has a responsibility to join others in lobbying for primary prevention programmes targeted at supporting families to care for and protect children in their early years (Davies \& Burdett, 2004). Similarly, as there is evidence that providing cognitive therapy to people at high risk is effective in reducing transition to psychosis (Morrison et al., 2004), it could be that early identification of young people with a trauma history and emerging psychotic experiences could be even more effective in preventing the development of psychotic disorders.

\section{CONCLUSIONS}

The link between trauma and psychosis has a clear body of empirical support, and the implications for treatment should be fairly uncontroversial, and could benefit service users regardless of the aetiology of their mental health problems. It is clearly important to consider the possible role of childhood trauma in the development and maintenance of distressing psychotic experiences and to ask about it. However, it is also important to remember that there are multiple pathways to psychosis, and while childhood trauma is clearly involved for some people with psychosis, there are many others with no history of trauma. Even is such instances, it is possible that these are prone to exacerbation and maintenance of their psychotic experiences through being traumatised by the subjective experience of psychosis or through subsequent victimisation in the community (Mueser et al., 2002; Walsh et al., 2003).

\section{REFERENCES}

Andrew E.M., Gray N.S. \& Snowden R.J. (2008). The relationship between trauma and beliefs about hearing voices: a study of psychiatric and non-psychiatric voice hearers. Psychological Medicine 38, 1409-1417.

Bak M., Krabbendam L., Janssen I., de Graaf R., Vollebergh W. \& van Os J. (2005). Early trauma may increase the risk for psychotic experiences by impacting on emotional response and perception of control. Acta Psychiatrica Scandinavica 112, 360-366.

Epidemiologia e Psichiatria Sociale, 18, 4, 2009 
Bebbington P. E., Bhugra D., Brugha T., Singleton N., Farrell M., Jenkins R., Lewis G. \& Meltzer H. (2004). Psychosis, victimisation and childhood disadvantage: Evidence from the second British National Survey of Psychiatric Morbidity. British Journal of Psychiatry 185, 220-226.

Bentall R. P. (2003). Madness Explained: Psychosis and Human Nature. Penguin Books Ltd: London.

Bentall R. P., Corcoran R., Howard R., Blackwood R. \& Kinderman P. (2001). Persecutory delusions: A review and theoretical integration. Clinical Psychology Review 22, 1-50.

Bernstein D.P., Fink L., Handelsman L., Foote J., Lovejoy M., Wenzel K., Sapareto E. \& Ruggiero J. (1994). Initial reliability and validity of a new retrospective measure of child abuse and neglect. American Journal of Psychiatry 151, 1132-1136.

Bifulco A., Bernazzani O., Moran P., \& Jacobs C. (2005). The Childhood Experience of Care and Abuse Questionnaire (CECA.Q) - Validation in a community series. British Journal of Clinical Psychology 44, 563-581.

Campbell M., \& Morrison A. P. (2007). The relationship between bullying, psychotic-like experiences and appraisals in 14-16 year olds. Behaviour Research and Therapy 45, 1579-1591.

Chadwick P. D., Birchwood M. J. \& Trower P. (1996). Cognitive Therapy for Delusions, Voices and Paranoia. Wiley: Chichester.

Davies E. \& Burdett J. (2004). Preventing 'schizophrenia': creating the conditions for saner societies. In Models of Madness: Psychological, Social and Biological Approaches to Schizophrenia (ed. J. Read, L.R. Mosher, R.P. Bentall). Brunner-Routledge: Hove.

Ehlers A. \& Clark D.M. (2000). A cognitive model of posttraumatic stress disorder. Behaviour Research and Therapy 38, 319-345.

Fowler D., Garety P. \& Kuipers E. (1995). Cognitive-Behaviour Therapy for Psychosis: Theory and Practice. Wiley: Chichester.

Frame L. \& Morrison A. P. (2001). Causes of post traumatic stress disorder in psychotic patients. Archives of General Psychiatry 58, 305306.

Garety P.A., Kuipers E., Fowler D., Freeman D. \& Bebbington P.E. (2001). A cognitive model of the positive symptoms of psychosis. Psychological Medicine 31, 189-195.

Green B. L. (1996). Trauma History Questionnaire. In Measurements of Stress, Trauma and Adaptation (ed. B.H. Stamm), pp. 366-368. Sidran: Lutherville, MD.

Honig A., Romme M.A.J., Ensink B.J., Escher S.D.M.A.C., Pennings M.H.A. \& DeVries M. W. (1998). Auditory hallucinations: A comparison between patients and nonpatients. Journal of Nervous and Mental Disease 186, 646-651.

Jackson C., Knott C., Skeate A. \& Birchwood M. (2004). The trauma of first episode psychosis: the role of cognitive mediation. Australian and New Zealand Journal of Psychiatry 38, 327-333.

Janssen I., Krabbendam L., Bak M., Hanssen M., Vollebergh W., de Graaf R. \& van Os J. (2004). Childhood abuse as a risk factor for psychotic experiences. Acta Psychiatrica Scandinavica 109, 38-45.

Johns L.C. \& van Os J. (2001). The continuity of psychotic experiences in the general population. Clinical Psychology Review 21, 11251141.

Katsakou C. \& Priebe S. (2007). Patient's experiences of involuntary hospital admission and treatment: a review of qualitative studies. Epidemiologia e Psichiatria Sociale 16, 172-178.

Kelleher I., Harley M., Lynch F., Arseneault L., Fitzpatrick C. \& Cannon M. (2008). Associations between childhood trauma, bullying and psychotic symptoms among a school-based adolescent sample. British Journal of Psychiatry 193, 378-382.

Kilcommons A. \& Morrison A.P. (2005). Relationships between trauma and psychosis: an exploration of cognitive and dissociative factors. Acta Psychiatrica Scandinavica 112, 351-359.

Kilcommons A., Morrison A.P., Knight A. \& Lobban F. (2008). Psychotic experiences in people who have been sexually assaulted. Social Psychiatry and Psychiatric Epidemiology 43, 602-611.

Kingdon D. \& Turkington D. (2005). Cognitive Therapy for Schizophrenia. Guilford Press: New York.
Kuipers E. \& Bebbington P. (2006). Cognitive behaviour therapy for psychosis. Epidemiologia e Psichiatria Sociale 15, 267-275.

Larkin W. \& Morrison A.P. (2006). Trauma and Psychosis: New Directions in Theory and Therapy. Taylor and Francis: London.

Lataster T., Van Os J., Drukker M., Henquet C., Feron F.J., Gunther N. \& Myin Germeys I. (2006). Childhood victimisation and developmental expression of non-clinical delusional ideation and hallucinatory experiences. Social Psychiatry and Psychiatric Epidemiology 41, 423-428.

McGorry P.D., Chanen A., McCarthy E., van Riel R., McKenzie D. \& Singh B.S. (1991). Post traumatic stress disorder following recent onset psychosis. Journal of Nervous and Mental Disease 179, 253258.

Morrison A.P. (2001). The interpretation of intrusions in psychosis: An integrative cognitive approach to hallucinations and delusions. Behavioural and Cognitive Psychotherapy 29, 257-276.

Morrison A. \& Petersen T. (2003). Trauma, metacognition and predisposition to hallucinations in non-patients. Behavioural and Cognitive Psychotherapy 31, 235-246.

Morrison A.P. \& Wells A. (2000). Thought control strategies in schizophrenia: A comparison with non-patients. Behaviour Research and Therapy 38, 1205-1209.

Morrison A.P., Frame L. \& Larkin W. (2003a). Relationships between trauma and psychosis: a review and integration. British Journal of Clinical Psychology 42, 331-353.

Morrison A.P., Renton J.C., Dunn H., Williams S. \& Bentall R.P. (2003b). Cognitive Therapy for Psychosis: a Formulation-based Approach. Psychology Press: London.

Morrison A.P., French P., Walford L., Lewis S.W., Kilcommons A., Green J., Parker S. \& Bentall R.P. (2004). Cognitive therapy for the prevention of psychosis in people at ultra-high risk: Randomised controlled trial. British Journal of Psychiatry 185, 291-297.

Morrison A.P., Gumley A. I., Schwannauer M., Campbell M., Gleeson A., Griffin E. \& Gillan K. (2005). The beliefs about paranoia scale: Preliminary validation of a metacognitive approach to conceptualising paranoia. Behavioural and Cognitive Psychotherapy 33, 153164.

Morrison A.P., Gumley A., Ashcroft K., Manousos R., White R. \& Kingdon D. (submitted for publication). Metacognition and persecutory delusions: A validation of the Beliefs about Paranoia Scale in a clinical population.

Mueser K.T., Goodman L.B., Trumbetta S.L., Rosenberg S.D., Osher F.C., Vidaver R., Auciello P. \& Foy D.W. (1998). Trauma and posttraumatic stress disorder in severe mental illness. Journal of Consulting and Clinical Psychology 66, 493-499.

Mueser K.T., Rosenberg S.D., Goodman L.A. \& Trumbetta S.L. (2002). Trauma, PTSD and the course of severe mental illness: an interactive model. Schizophrenia Research 53, 123-143.

Read J. (1997). Child abuse and psychosis: A literature review and implications for professional practice. Professional Psychology: Research and Practice 28, 448-456.

Read J. \& Fraser A. (1998a). Abuse histories of psychiatric inpatients: to ask or not to ask? Psychiatric Services 49, 355-359.

Read J. \& Fraser A. (1998b). Staff response to abuse histories of psychiatric inpatients. Australian and New Zealand Journal of Psychiatry 32, 206-213.

Read J. \& Haslam N. (2004). Public opinion: bad things happen and can drive you crazy. In Models of Madness (ed. J. Read, L.R. Mosher, R.P. Bentall), pp. 133-145. Bruner-Routledge: Hove.

Read J., Perry B.D., Moskowitz A. \& Connolly J. (2001). The contribution of early traumatic events to schizophrenia in some patients: a traumagenic neurodevelopmental model. Psychiatry: Interpersonal and Biological Processes 64, 319-345.

Read J., Goodman L.A., Morrison A.P., Ross C.A. \& Aderhold V. (2004). Childhood trauma, loss and stress. In Models of Madness (ed. J. Read, L.R. Mosher, R.P. Bentall). Bruner-Routledge: Hove.

Epidemiologia e Psichiatria Sociale, 18, 4, 2009 
Read J., van Os J., Morrison A.P. \& Ross C.A. (2005). Childhood trauma, psychosis and schizophrenia: a literature review and clinical implications. Acta Psychiatrica Scandinavica 112, 330-350.

Reynolds M. \& Wells A. (1999). The thought control questionnaire: Psychometric properties in a clinical sample, and relationships with PTSD and depression. Psychological Medicine 29, 10891099.

Scott J., Chant D., Andrews G., Martin G. \& McGrath J. (2007). Association between trauma exposure and delusional experiences in a large community-based sample. British Journal of Psychiatry 190, 339-343.

Shevlin M., Dorahy M.J. \& Adamson G. (2007). Trauma and psychosis: An analysis of the National Comorbidity Survey. American Journal of Psychiatry 164, 166-169.

Thompson J.L., Kelly M., Kimhy D., Harkavy-Friedman J.M., Khan S., Messinger J.W., Schobel S., Goetz R., Malaspina D. \& Corcoran C.
(2009). Childhood trauma and prodromal symptoms among individuals at clinical high risk for psychosis. Schizophrenia Research 108, 176-181.

Van Os J. (2003). Is there a continuum of psychotic experiences in the general population? Epidemiologia e Psichiatria Sociale 12, 242252.

Walsh E., Moran P., Scott C., McKenzie K., Burns T., Creed F., Tyrer P., Murray R.M. \& Fahy T. (2003). Prevalence of violent victimisation in severe mental illness. British Journal of Psychiatry 183, 233238.

Whitfield C.L., Dube S.R., Felitti V.J. \& Anda R. (2005). Adverse childhood experiences and hallucinations. Child Abuse Neglect 29, 797-810.

Young M., Read J., Barker-Collo S. \& Harrison R. (2001). Evaluating and overcoming barriers to taking abuse histories. Professional Psychology: Research and Practice 32, 407-414. 